\title{
The Effects of Infusion of Water on Renal Hemodynamics and the Tubular Reabsorption of Sodium*
}

\author{
Joseph A. Martino and Laurence E. Earley $\dagger$ \\ (From the Thorndike Memorial Laboratory, Second and Fourth [Harvard] Medical Services, \\ Boston City Hospital, and the Department of Medicine, Harvard Medical School, \\ Boston, Mass.)
}

Summary. Anesthetized dogs receiving an infusion of chlorothiazide and ethacrynic acid were given $600-\mathrm{ml}$ infusions of distilled water or dilute dextrose solutions. The absolute rate of tubular sodium reabsorption was depressed, and the glomerular filtration rate was increased during the water loading, despite the associated decreases in plasma sodium concentration and decreases in the filtered load of sodium. The extent to which fractional sodium reabsorption decreased and the excretion of sodium increased was inversely related to the degree to which the filtered load of sodium was depressed as a result of the decreased plasma sodium concentration. We conclude that, in the presence of the diuretic blockade of distal tubular sodium reabsorption, infusion of water depresses proximal tubular reabsorption of sodium and that these changes are qualitatively similar to those previously observed during infusions of saline. Similar depression of tubular reabsorption of sodium and increased excretion of sodium occurred during water loading in the absence of diuretics in dogs undergoing saline diuresis, which presumably provided a high rate of distal sodium reabsorption before water loading.

We suggest that volume expansion with water depresses proximal tubular reabsorption of sodium in a manner qualitatively similar to infusions of saline and that the extent to which sodium excretion is increased during water loading is dependent upon 1) the absolute extent to which proximal reabsorption is depressed, 2) the extent to which the filtered load of sodium is maintained in the presence of a falling concentration of sodium in plasma, and 3) the extent to which increased distal reabsorption compensates for the depressed proximal reabsorption of sodium. Mechanisms are suggested whereby the previously reported inverse relationship between plasma concentration of sodium and over-all tubular reabsorption of sodium may be only apparent, and could be the result of physiologic "glomerulotubular balance" during the specific experimental maneuvers.

\section{Introduction}

It has been established in the dog that expansion of the extracellular fluid volume by infusing saline depresses the over-all tubular reabsorption of

* Submitted for publication January 31, 1967 ; accepted April 11, 1967.

Aided in part by grants AM-5401-06 from the National Institutes of Health and NsG595 from the National Aeronautics and Space Administration. sodium (1-4), and micropuncture studies by Dirks, Cirksena, and Berliner have indicated that this depressed reabsorption occurs in the proximal tubule (5). Studies from our laboratory have

$\dagger$ Recipient of U. S. Public Health Service Career Development Award 1-K3-AM-13,821-01.

Address requests for reprints to Dr. Laurence $\mathrm{E}$. Earley, Thorndike Memorial Laboratory, Boston City Hospital, 818 Harrison Ave., Boston, Mass. 02118. 
demonstrated that in the presence of reduced renal vascular resistance over-all tubular reabsorption of sodium may relate inversely to renal perfusion pressure $(6,7)$ and also that proximal tubular reabsorption of sodium may relate directly to plasma oncotic pressure (7). Since infusions of saline lower plasma oncotic pressure and may increase arterial pressure and lower renal vascular resistance, we have suggested that these physical changes may be involved in the depression of proximal tubular reabsorption of sodium during infusions of saline (6-8). If so, then infusions of water without sodium also should result in demonstrable depressions of proximal tubular reabsorption, since similar hemodynamic and compositional changes may occur. It is recognized that the simultaneous administration of water and vasopressin, which maintains volume expansion, results in increased excretion of sodium and negative sodium balance (9), and the same may occur pathologically in patients with syndromes limiting their ability to excrete ingested water $(10,11)$. Also, micropuncture studies by Clapp, Watson, and Berliner indicated that volume reabsorption by the proximal tubule may be depressed in water-loaded dogs when compared to a group of hydropenic animals (12). However, certain evidence has been presented recently that hyponatremia per se during water loading may result in increased tubular reabsorption and decreased excretion of sodium despite simultaneous volume expansion (13). Therefore, the present studies were designed to re-examine the effect of volume expansion with water on sodium reabsorption and excretion, utilizing a previously described technique of distal tubular blockade, which, to some extent, permits evaluation of reabsorptive changes occurring in the proximal tubule. The results indicate that infusions of water have the same qualitative effects to depress proximal tubular reabsorption of sodium as do infusions of saline.

\section{Methods}

Studies were carried out in 18 mongrel dogs of either sex, ranging in weight from 12.7 to $18.6 \mathrm{~kg}$. The animals were anesthetized with pentobarbital and ventilated through an endotracheal tube connected to a Harvard respirator. ${ }^{1}$ Fifteen animals were deprived of water for 12 hours and received by im injection $10 \mathrm{mg}$ deoxycorti-

1 Harvard Apparatus, Dover, Mass. costerone acetate, and $5 \mathrm{U}$ vasopressin, in oil approximately 4 hours before experimental collections. Ureters were cannulated with polyethylene tubing through flank incisions, and a plastic catheter was inserted into the left renal vein in the direction of the kidney, usually via the ovarian or spermatic vein. Polyethylene catheters were inserted into a femoral artery and vein for measurements of aortic and inferior vena caval pressures, with Sanborn pressure transducers and recorder, and for withdrawal of arterial blood samples. At least 2 hours before experimental collections an iv infusion was begun at 0.3 to $0.4 \mathrm{ml}$ per minute to deliver inulin and $p$-aminohippurate $(\mathrm{PAH})$ in amounts adequate for clearance measurements. In 15 studies this maintenance infusion also contained deoxycorticosterone (20 to $30 \mu \mathrm{g}$ per minute) and vasopressin ( 30 to $40 \mathrm{mU}$ per $\mathrm{kg}$ per hour). Approximately 1 hour before experimental collections "distal tubular blockade" as previously described (7) was instituted in 12 of the experiments. This was accomplished by an acute iv injection of $250 \mathrm{mg}$ chlorothiazide and $50 \mathrm{mg}$ ethacrynic acid, ${ }^{2}$ followed by a maintenance infusion of $250 \mathrm{mg}$ chlorothiazide and $50 \mathrm{mg}$ ethacrynic acid per hour. The diuretic-induced urinary losses were replaced quantitatively by the iv infusion of an isotonic solution containing $\mathrm{Na} 145, \mathrm{~K} 4.5, \mathrm{Cl} 129.5$, and $\mathrm{HCO}_{3}$, $20 \mathrm{mEq}$ per $\mathrm{L}$. Once the rate of this replacement solution had been adjusted (during the first 30 minutes after beginning the diuretics) to replace urinary losses, it was infused at a constant rate throughout the remainder of the experiment, independent of any other experimental maneuvers. After urine had been collected for 3 to 7 clearance periods, experiments were continued according to one of the following protocols.

Water loading with distal tubular blockade alone. After control collections during diuretic blockade alone 8 animals received an infusion of $600 \mathrm{ml}$ of $1 \%$ dextrose in water at $30 \mathrm{ml}$ per minute, after which an infusion of distilled water was continued at 5 to $20 \mathrm{ml}$ per minute. ${ }^{3}$ Thirty to 60 minutes after this loading procedure had begun, collections were taken for an additional 5 to 7 periods. In 4 of these experiments the animals were not deprived of water before the study, nor did they receive vasopressin and deoxycorticosterone. In 2 of these stud-

2 Ethacrynic acid and chlorothiazide were kindly supplied by Dr. William H. Wilkinson of Merck Sharp \& Dohme Research Laboratories, West Point, Pa.

3 The high rate of infusion of isotonic solution for replacement of diuretic-induced losses permitted the infusion of $1 \%$ dextrose or distilled water through the same iv catheter with little or no hemolysis. In some experiments water loading was accomplished by appropriately diluting the isotonic replacement solution with distilled water and increasing the rate of infusion to provide the same replacement of electrolytes plus the additional load of water. In some experiments in which the dextrose solution was infused, slight glycosuria occurred. However, no experimental collections were taken until urinary glucose was absent as determined by Clinitest reactions. 
ies, after collections following the water load, vasopressin was administered by injecting $200 \mathrm{mU}$ intravenously followed by an infusion of 1,000 $\mathrm{mU}$ per hour, after which additional collections were made. The remaining 4 animals were deprived of water before the experiment and received deoxycorticosterone and vasopressin as described above.

Saline loading followed by water loading during distal blockade. In 4 experiments after collections during infusion of diuretics and replacement of urinary losses, the animals received a $600-\mathrm{ml}$ infusion of isotonic Ringer's solution (the same solution described above for replacement of urinary losses) at $30 \mathrm{ml}$ per minute, which afterwards was continued at 10 to $20 \mathrm{ml}$ per minute. Thirty to 40 minutes after initiation of this infusion of saline additional collections were taken. The water loading procedure described above was then begun, and further collections were taken.

Saline loading followed by water loading in the absence of distal blockade. Six experiments were performed without the administration of chlorothiazide and ethacrynic acid. After control collections the animals received $600 \mathrm{ml}$ of the Ringer's solution at $30 \mathrm{ml}$ per minute, which afterwards was continued at $10 \mathrm{ml}$ per minute. Additional collections were made during the saline infusion, after which the animals received the water load as described above, and collections were continued.

In each of the protocols clearance periods were usually 5 minutes in duration, except during antidiuretic periods when urine flow was low. Samples of arterial blood were withdrawn during alternate periods, and no collections for clearances were made after experimental maneuvers until urine flow rates had stabilized. Mean arterial pressure was recorded at the begnning of each clearance period.

Inulin, PAH, osmolality, sodium, and potassium were determined by methods previously described for this laboratory (8). Total protein in plasma was determined by a modification of the biuret method (14), and hematocrits were measured by the standard Wintrobe technique. Renal plasma flow (RPF) was calculated by the formula of Wolf (15): $R P F=[V(U-R)] /$ $(A-R)$, where $V=$ rate of urine flow and $U$ urinary, $R$ renal venous, and $A$ arterial concentrations of PAH. Renal blood flow $(\mathrm{RBF})=\mathrm{RPF} /(1-0.95$ hematocrit $)$. Filtered sodium $\left(\mathrm{F}_{\mathrm{Na}}\right)$ was calculated as the product of the glomerular filtration rate (GFR) and the concentration of sodium in plasma $\left(\mathrm{P}_{\mathrm{Na}}\right)$. Tubular reabsorption of sodium $\left(T_{N_{a}}\right)=F_{N_{a}}-U_{N_{a}} V\left(U_{N_{a} V}=\right.$ urinary sodium excretion), and fractional reabsorption $=\mathrm{T}_{\mathrm{Na}} / \mathrm{F}_{\mathrm{Na}}$. Changes in fractional reabsorption are expressed as percentage, and $=\left(\mathrm{T}_{\mathrm{Na}_{1}} / \mathrm{F}_{\mathrm{Na} 1}\right) \times 100 /\left(\mathrm{T}_{\mathrm{Na}_{2}} / \mathrm{F}_{\mathrm{Na}_{2}}\right)$.

\section{Results}

Effects of diuretics alone. During the steady state effect of chlorothiazide and ethacrynic acid mean arterial pressure averaged $113 \mathrm{~mm} \mathrm{Hg}$, $\mathrm{RBF}$ averaged $248 \mathrm{ml}$ per minute per kidney, and left renal vascular resistance averaged $0.51 \mathrm{~mm}$ $\mathrm{Hg}$ per $\mathrm{ml}$ per minute. GFR averaged $25 \mathrm{ml}$ per minute per kidney, and the fractional reabsorption of sodium averaged 0.66. These values are in close agreement with those previously observed under similar conditions (7).

Effects of infusion of water in the presence of distal tubular blockade. In 4 experiments water loads were infused during distal tubular blockade (infusion of chlorothiazide and ethacrynic acid) in animals not receiving vasopressin or deoxycorticosterone and in 4 animals receiving these hormones. Details of a representative experiment from each of these groups are given in Tables I and II. In the absence of vasopressin the infusion of water was associated with a decrease in mean arterial pressure averaging $-10 \mathrm{~mm} \mathrm{Hg}$ (range -3 to $-15 \mathrm{~mm} \mathrm{Hg}$ ) and decreased RBF averaging $-27 \mathrm{ml}$ per minute (range -13 to -46 $\mathrm{ml}$ per minute). In the presence of vasopressin and deoxycorticosterone mean arterial pressure during the infusion of water was largely unchanged (range +1 to $+6 \mathrm{~mm} \mathrm{Hg}$ ), and RBF increased an average of $40 \mathrm{ml}$ per minute per kidney (range +1 to $+90 \mathrm{ml}$ per minute). In the absence of the hormones GFR during water loading increased an average of $9 \%$ (range +2 to $+4 \mathrm{ml}$ per minute per kidney), and in the presence of the hormones GFR increased somewhat more $(+17 \%$, range +2 to $+7 \mathrm{ml}$ per minute per kidney). Plasma sodium during water loading decreased an average of $18 \mathrm{mEq}$ per $\mathrm{L}$ in the absence of vasopressin and deoxycorticosterone and an average of $19 \mathrm{mEq}$ per $\mathrm{L}$ in the presence of the hormones. Thus, in the animals receiving vasopressin and deoxycorticosterone, arterial pressure, $\mathrm{RBF}$, and GFR during the infusion of water were greater than in the animals not receiving these agents. The effects of the infusion of water on sodium reabsorption and excretion were qualitatively similar in both groups of animals. However, because of the greater increases in GFR in the animals receiving vasopressin and deoxycorticosterone the filtered load of sodium was decreased less than in the untreated group (Figures 1 and 2). Despite increases in GFR, the filtered load of sodium was depressed below control due to the fall in plasma sodium concentration in 10 of the 16 kidneys of these 8 experiments. During the infusion of water the absolute rate of reabsorption of sodium was 


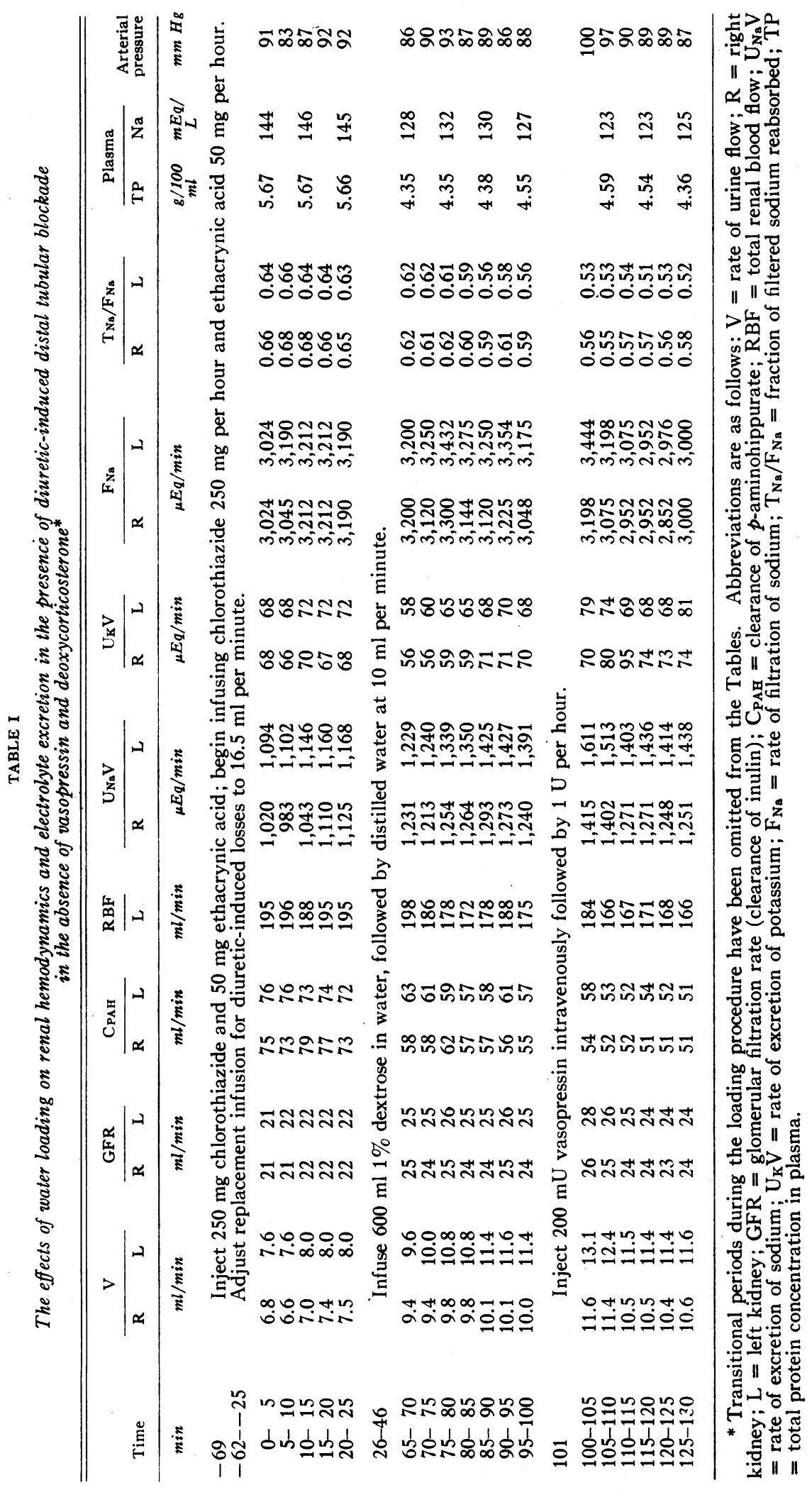




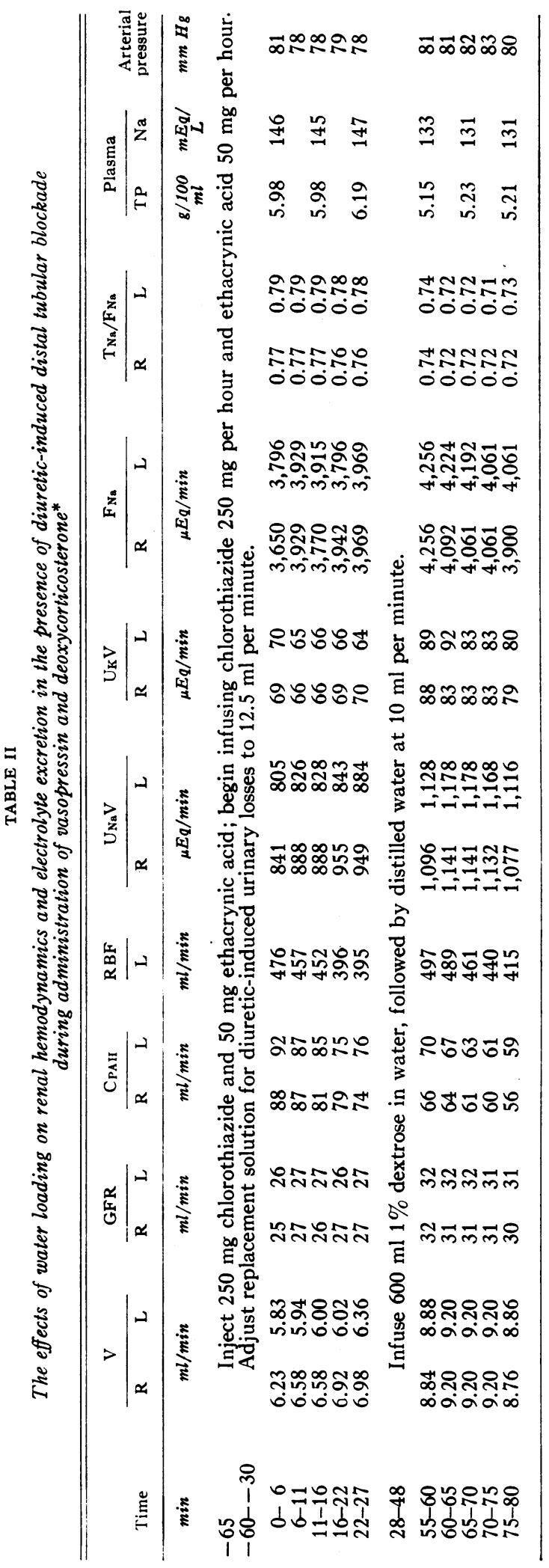

decreased in 14 of the 16 kidneys, and the absolute rate of excretion of sodium was increased in 12 of the kidneys. Although the rate of tubular reabsorption of sodium was decreased in all but 2 of the experiments, the changes in excretion of sodium appeared directly related to the changes in the rate of filtration of sodium, and during the infusion of water the experiments in which there was a decrease, or at least no increase, in the excretion of sodium were the ones in which the filtered load of sodium underwent the larger decreases (Figure 1). When vasopressin was infused in the presence of water loading, there was a transient increase in arterial pressure, GFR, and sodium excretion. However, when arterial pressure and GFR returned to the prior values, there was no evidence that administration of the hormone had any effect on sodium reabsorption and excretion (Table I).

The decreases in absolute tubular reabsorption of sodium during the infusion of water were not the result of limited rates of filtered sodium, since

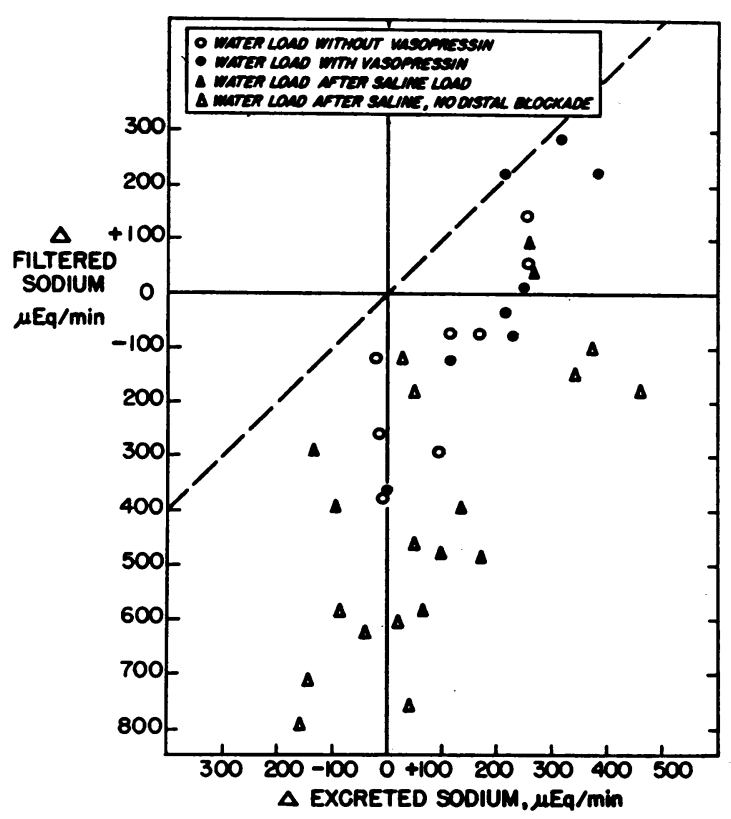

Fig. 1. EFfects of WATER LOAding on FILTEREd AND EXCRETED SODIUM. Each point is the mean of multiple consecutive collections from indivdual kidneys and represents the change from the mean of multiple collections before infusing the water load. The broken diagonal line indicates unity, and all points below this line indicate absolute decreases in tubular reabsorption of sodium. All points to the right of the solid vertical line indicate increased excretion of sodium. 


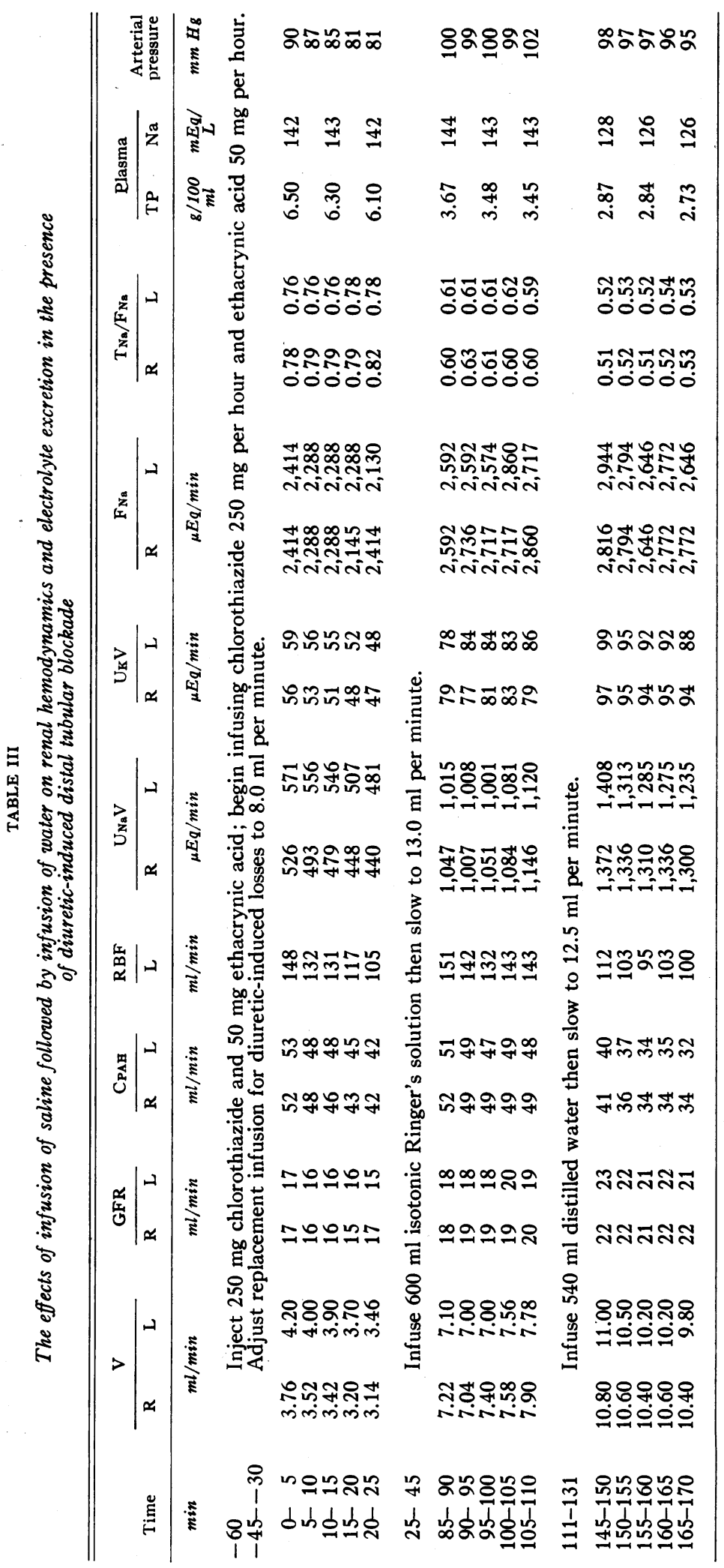




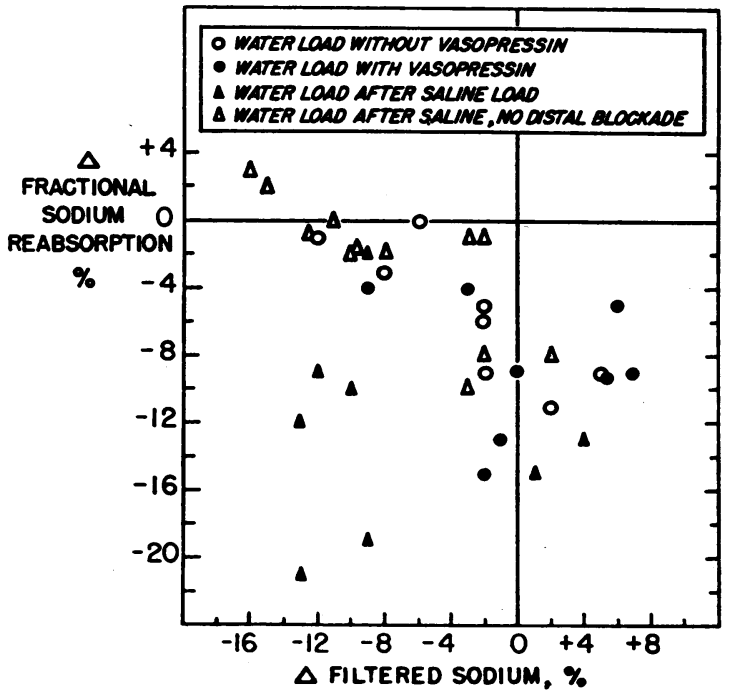

Fig. 2. EFFECTS OF WATER LOADING ON THE FRACTIONAL REABSORPTION OF SODIUM. Points are the means of the same collection periods shown in Figure 1 . The fractional reabsorption of sodium usually decreased during water loading in each of the experimental designs, despite decreases in the filtered load of sodium in most of the studies.

tubular reabsorption was depressed by the infusion whether or not large decreases in the filtered load of sodium occurred (Figure 1). Furthermore, in all experiments large amounts of sodium still escaped tubular reabsorption to appear in the urine, despite the decreases in the filtered load of sodium in some experiments.

Effects of infusion of water in saline-loaded animals, with and without distal tubular blockade. In 4 studies after control collections during infusion of chlorothiazide and ethacrynic acid the animals received a $600-\mathrm{ml}$ infusion of isotonic Ringer's solution (see Methods) at $30 \mathrm{ml}$ per minute, which afterwards was continued at $10 \mathrm{ml}$ per minute. This infusion of "saline" resulted in increases in sodium excretion averaging $732 \mu \mathrm{Eq}$ per minute, and in each of these studies the absolute rate of sodium reabsorption was depressed during the infusion of saline (Table III). Fractional reabsorption of sodium decreased an average of $23 \%$. After collections during the saline infusion the animals then received an additional $600 \mathrm{ml}$ of water at $30 \mathrm{ml}$ per minute, which afterwards was continued at 10 to $12 \mathrm{ml}$ per minute. The infusions of water resulted in decreases in plasma sodium concentration averaging $19 \mathrm{mEq}$ per L,

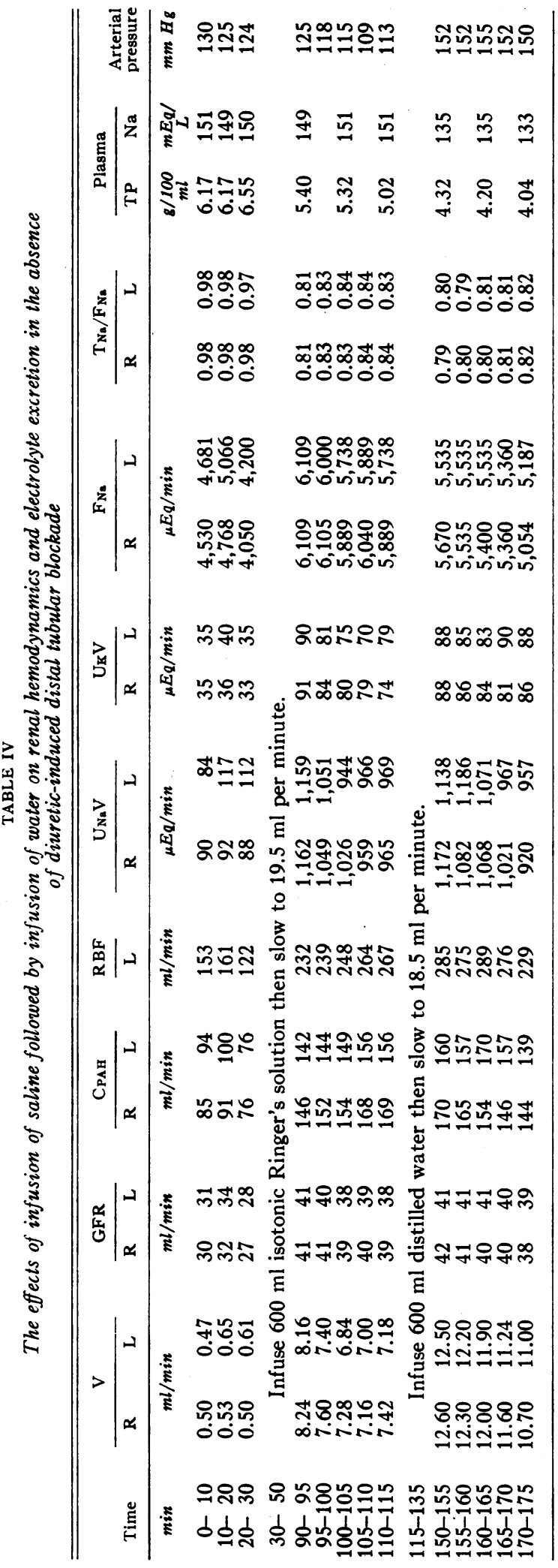


and the filtered load of sodium was decreased in 7 of the 8 kidneys of these experiments. Despite the falls in plasma sodium concentration and the filtered load of sodium, the excretion of sodium increased during the infusion of water in 6 of the 8 kidneys (range -133 to $+264 \mu \mathrm{Eq}$ per minute). The fractional reabsorption of sodium was depressed an average of $13 \%$ (range -2 to $-21 \%$ ) during the water loading. The changes in filtered and excreted sodium produced by the infusion of water in these 4 animals are summarized in Figure 1 , and details of a representative experiment are given in Table III.

In six similar studies chlorothiazide and ethacrynic acid were not administered, and after control collections during hydropenia the animals received the saline infusion as described above. When urinary flow rates were stable in the presence of the saline load, the additional $600-\mathrm{ml}$ infusion of water was given. Details of one of these experiments without distal tubular blockade are given in Table IV. In these studies without diuretics the infusion of water resulted in changes in plasma sodium concentration, GFR, filtered sodium, and sodium excretion similar to those observed in the presence of the infusion of the diuretics (Table IV, Figures 1 and 2).

\section{Discussion}

The present results demonstrate that infusions of relatively small volumes of water result in a depression of tubular reabsorption of sodium. In each study there was a decrease in the absolute amount of sodium reabsorbed during the infusion of water, and in most studies this was manifested by decreased fractional reabsorption and increased excretion of sodium, despite decreased filtered loads of sodium in most of the experiments. Decreases in fractional sodium reabsorption and increases in excreted sodium occurred in those experiments with the smaller decreases in the filtered load of sodium. Since the combination of ethacrynic acid and chlorothiazide may interfere with the major part of sodium reabsorption beyond the proximal tubule $(7,16,17)$, the changes in reabsorption observed in the present study probably are attributable to changes occurring in the proximal tubule. The factors upon which such a conclusion is based have been discussed in detail in a previous publication from this labortory (7). It may be concluded, therefore, that in these studies volume expansion with water produced changes in tubular sodium reabsorption qualitatively similar to those observed during infusions of saline (7). Even when there was no absolute increase in sodium excretion during water loading, there was an absolute depression in "proximal" reabsorption of sodium. This fall in absolute reabsorption cannot be attributed solely to associated falls in the filtered load of sodium since large amounts of sodium still escaped proximal reabsorption to appear in the urine. If it is correct that the diuretics have no net effect on proximal reabsorption of sodium (16), then the decreased filtered load of sodium per se was not adequate to limit the amount of sodium available for proximal reabsorption during the infusion of water. In none of the present experiments was there any evidence that the decreased concentration of sodium in plasma resulting from the infusion of water was associated with increased tubular reabsorption of sodium. Whether the infusion of water was given in the presence or absence of saline loading, or in the presence or absence of the diuretic agents, the absolute rate of sodium reabsorption was depressed.

In contrast to the present observations, Blythe and Welt have reported that hyponatremia produced by infusing a dextrose solution into dogs previously loaded with saline resulted in increased tubular sodium reabsorption and decreased sodium excretion (13). In their studies GFR was depressed (by aortic occlusion) during saline loading and was allowed to increase during the hyponatremic phase in order to maintain a constant filtered load of sodium despite different plasma concentrations of sodium. The studies of Dirks and his associates have demonstrated that in the salineloaded dog changes in GFR (by renal arterial occlusion) are accompanied by proportional changes in the absolute rate of proximal tubular sodium reabsorption resulting in a constant fractional reabsorption (5). Such "glomerulotubular balance" could relate to changes in the volume of filtrate rather than to changes in the filtered load of sodium per se, and the likelihood of such a relationship is supported by studies demonstrating a proportionality between proximal tubular volume and the absolute rate of proximal reabsorption $(18,19)$. Therefore, when the filtered volume 
was allowed to increase during hyponatremia in the studies of Blythe and Welt (13), the absolute rate of proximal reabsorption could increase in response to the larger filtered volume and resultant tubular distension, and the proximal reabsorption of sodium would be increased despite a relatively constant filtered load of sodium. Such an interpretation does not require that hyponatremia per se have any direct effect on tubular sodium reabsorption, and such an interpretation is entirely compatible with the presently observed relationships between GFR, filtered sodium, proximal fractional reabsorption, absolute sodium reabsorption, and sodium excretion during water loading and hyponatremia.

A similar line of reasoning could account for the results of experiments designed to demonstrate that hypernatremia depresses the reabsorption of sodium $(20,21)$. In the studies of Kamm and Levinsky (21) kidney circuits were infused with hypertonic saline, and GFR was depressed simultaneously to maintain a lowered filtered load of sodium. Therefore, if the absolute rate of proximal tubular reabsorption relates in some manner to the filtered volume (as discussed above), the rate of proximal sodium reabsorption will be depressed when the filtered load of sodium is kept constant (by decreased GFR) as plasma sodium concentration increases. It may not matter whether the compensating decrease in GFR is produced experimentally or occurs spontaneously as plasma sodium concentration is increased (21). Again, this mechanism would not require that hypernatremia have any direct effect to depress proximal tubular sodium transport. Other observations suggest that hypernatremia may facilitate distal tubular transport of sodium as judged by increases in concentrating capacity $\left(\mathrm{T}^{\mathrm{c}}{ }_{\mathrm{H}_{2} \mathrm{O}}\right)$ during infusion of hypertonic saline $(22,23)$.

On the basis of the present results and the above conclusions, we suggest that volume expansion with water has the same qualitative effect as expansion with saline to depress tubular sodium reabsorption. Therefore, whether volume expansion with water increases the excretion of sodium would depend upon 1) the extent to which absolute reabsorption by the proximal tubule is depressed by the water load, 2) the extent to which the filtered load of sodium is maintained in the presence of a falling serum sodium, and 3) the extent to which sodium rejected from proximal reabsorption is recaptured by distal tubular reabsorption. These observations do not exclude the possibility that decreases in plasma sodium concentration have some more direct effect on distal tubular sodium reabsorption, which over-all is greater than the effect of the associated volume expansion to depress proximal sodium reabsorption. If so, then the present experimental designs could have permitted demonstration of the effect of volume expansion to depress proximal reabsorption (despite hyponatremia), because of either the drug-induced blockade of distal reabsorption or the "overloading" of distal reabsorption by prior saline diuresis. However, the interpretations outlined above do not require that plasma sodium concentration have any special effect on either proximal or distal tubular sodium transport.

If the above conclusions are correct, then the sodium wasting and negative sodium balance associated with the chronic retention of water (9-11), and occurring independent of adrenal hormones (24), could result from the effect of volume expansion to depress proximal tubular sodium reabsorption through the same pathways as does volume expansion with saline.

\section{Acknowledgments}

We are grateful for the assistance of Susan Howard and Helen Flanagan.

\section{References}

1. De Wardner, H. E., I. H. Mills, W. F. Clapham, and C. J. Hayter. Studies on the efferent mechanism of the sodium diuresis which follows the administration of intravenous saline in the dog. Clin. Sci. 1961, 21, 249.

2. Levinsky, N. G., and R. C. Lalone. The mechanism of sodium diuresis after saline infusion in the dog. J. clin. Invest. 1963, 42, 1261.

3. Rector, F. C., Jr., G. Van Giesen, F. Kiil, and D. W. Seldin. Influence of expansion of extracellular volume on tubular reabsorption of sodium independent of changes in glomerular filtration rate and aldosterone activity. J. clin. Invest. 1964, 43, 341 .

4. Earley, L. E., and R. M. Friedler. Observations on the mechanism of decreased tubular reabsorption of sodium and water during saline loading. J. clin. Invest. 1964, 43, 1928.

5. Dirks, J. H., W. J. Cirksena, and R. W. Berliner. The effect of saline infusion on sodium reabsorption by the proximal tubule of the dog. J. clin. Invest. 1965, 44, 1160. 
6. Earley, L. E., and R. M. Friedler. The effects of combined renal vasodilatation and pressor agents on renal hemodynamics and the tubular reabsorption of sodium. J. clin. Invest. 1966, 45, 542.

7. Earley, L. E., J. A. Martino, and R. M. Friedler. Factors affecting sodium reabsorption by the proximal tubule as determined during blockade of distal sodium reabsorption. J. clin. Invest. 1966, 45, 1668.

8. Earley, L. E., and R. M. Friedler. Studies on the mechanism of natriuresis accompanying increased renal blood flow and its role in the renal response to extracellular volume expansion. J. clin. Invest. 1965, 44, 1857.

9. Leaf, A., F. C. Bartter, R. F. Santos, and O. Wrong. Evidence in man that urinary electrolyte loss induced by Pitressin is a function of water retention. J. clin. Invest. 1953, 32, 868.

10. Schwartz, W. B., W. Bennett, S. Curelop, and F. C. Bartter. A syndrome of renal sodium loss and hyponatremia probably resulting from inappropriate secretion of antidiuretic hormone. Amer. J. Med. 1957, 23, 529.

11. Schwartz, W. B., D. Tassel, and F. C. Bartter. Further observations on hyponatremia and renal sodium loss probably resulting from inappropriate secretion of antidiuretic hormone. New Engl. J. Med. 1960, 262, 743.

12. Clapp, J. R., J. F. Watson, and R. W. Berliner. Osmolality, bicarbonate concentration, and water reabsorption in proximal tubule of the dog nephron. Amer. J. Physiol. 1963, 205, 273.

13. Blythe, W. B., and L. G. Welt. Plasma sodium concentrations and urinary sodium excretion. Trans. Ass. Amer. Phycns. 1965, 78, 90.

14. Gornall, A. G., C. J. Bardawill, and M. M. David. Determination of serum proteins by means of the biuret reaction. J. biol. Chem. 1949, 177, 751.
15. Wolf, A. V. Total renal blood flow at any urine flow or extraction fraction (abstract). Amer. J. Physiol. 1941, 133, 496.

16. Dirks, J. H., W. H. Cirksena, and R. W. Berliner. Micropuncture study of the effect of various diuretics on sodium reabsorption by the proximal tubules of the dog. J. clin. Invest. 1966, 45, 1875.

17. Earley, L. E., and R. M. Friedler. Renal tubular effects of ethacrynic acid. J. clin. Invest. 1964, 43, 1495.

18. Gertz, K. H. Transtubuläre Natriumchloridflüsse und Permeabilität für Nichtelektrolyte im proximalen und distalen Konvolut der Rattenniere. Pflügers Arch. ges. Physiol. 1963, 276, 336.

19. Rector, F. C., Jr., F. P. Brunner, and D. W. Seldin. Mechanism of glomerulotubular balance. I. Effect of aortic constriction and elevated ureteropelvic pressure on glomerular filtration rate, fractional reabsorption, transit time, and tubular size in the proximal tubule of the rat. J. clin. Invest. 1966, 45, 590.

20. Blythe, W. B., and L. G. Welt. Dissociation between filtered load of sodium and its rate of excretion in the urine. J. clin. Invest. 1963, 42, 1491.

21. Kamm, D. E., and N. G. Levinksy. Inhibition of renal tubular sodium reabsorption by hypernatremia. J. clin. Invest. 1965, 44, 1144.

22. Goldberg, M., D. K. McCurdy, and M. A. Ramirez. Differences between saline and mannitol diuresis in hydropenic man. J. clin. Invest. 1965, 44, 182.

23. Friedler, R. M., and L. E. Earley. Reduced renal concentrating capacity during isotonic saline loading. Proc. Soc. exp. Biol. (N. Y.) 1966, 121, 352.

24. Levinsky, N. G., D. G. Davidson, and R. W. Berliner. Changes in urine concentration during prolonged administration of vasopressin and water. Amer. J. Physiol. 1959, 196, 451. 